\title{
Professional practice environment and nursing work stress in neonatal units*
}

\author{
Ambiente de prática profissional e estresse no trabalho da enfermagem \\ em unidades neonatais \\ Ambiente de práctica profesional y estrés en el trabajo \\ de enfermería en las unidades neonatales
}

How to cite this article:

Lopes RP, Oliveira RM, Gomes MSB, Santiago JCS, Silva RCR, Souza FL. Professional practice environment and nursing work stress in neonatal units. Rev Esc Enferm USP. 2021;55:e20200539. DOI: https://doi.org/10.1590/1980-220X-REEUSP-2020-0539

\section{Raquel Pereira Lopes ${ }^{1}$ \\ Roberta Meneses Oliveira ${ }^{1}$ \\ Maria Salete de Brito Gomes ${ }^{1}$ \\ Jênifa Cavalcante dos Santos Santiago ${ }^{1}$ \\ Renata Celly Rodrigues Silva ${ }^{2}$ \\ Fábio Lopes de Souza ${ }^{2}$}

* Extracted from the thesis: "Ambiente de prática profissional, qualidade do cuidado e estresse no trabalho da equipe de enfermagem em unidades neonatais: análise multidimensional e plano de ação", Universidade Estadual do Ceará, Programa de Pós-Graduação, 2018.

${ }^{1}$ Universidade Estadual do Ceará, Programa de Pós-Graduação Mestrado Profissional em Saúde da Criança e do Adolescente, Fortaleza, CE, Brazil.

${ }^{2}$ Universidade Federal do Ceará, Faculdade de Farmácia, Odontologia e Enfermagem, Departamento de Enfermagem, Fortaleza, CE, Brazil.

\begin{abstract}
Objective: To assess the nurse professional practice environment of neonatal units and its relationship with the levels and main sources of occupational stress. Method: Cross-sectional descriptive, exploratory, correlational study performed with nursing professionals of neonatal units of four public hospitals. A sociodemographic/ professional questionnaire, the Brazilian version of Practice Environment Scale, and the Work Stress Scale were applied. In the analysis, mean, standard deviation, and Pearson chi-squared, Likelihood Ratio, and Mann Whitney U tests were adopted for association among variables. Results: Participating professionals amounted to 269. The practice environment was evaluated as favorable by more than half of the sample (63.6\%), showing a significant statistical association which was inversely proportional with occupational stress $(\mathrm{p}<0.001)$. The insufficient number of professionals for quality care was the major source of stress for nursing technicians, whereas teamwork with doctors was the predominant factor for the evaluation of environment quality and high stress levels of nurses. Conclusion: Unfavorable practice environments increase the stress levels of nursing professionals in neonatal units and may compromise patient safety.
\end{abstract}

\section{DESCRIPTORS}

Neonatal Nursing; Working Environment; Occupational Stress; Physician-Nurse Relations; Intensive Care Units, Neonatal. 


\section{INTRODUCTION}

The nursing professional practice environment is defined by the different factors that improve or reduce professional capability of proficiently performing nursing skills and providing high-quality care to patients ${ }^{(1)}$. These factors considerably impact the results of patient care ${ }^{(2-4)}$.

Among the factors that negatively influence the practice environment in hospitals, occupational stress is emphasized. This is an emotional and physical condition which may have harmful effects and often leads to incapacity of meeting necessities, resources, and capabilities which are demanded from workers ${ }^{(5)}$. This is a major global issue in the health area and is considered to have become a main management challenge in the last decades ${ }^{(6-7)}$.

The high prevalence of occupational stress in Nursing demonstrates the magnitude of this problem for professionals in this area and their patients, despite the recently implemented reforms of various countries. In general, the main stressors in nursing include shift work, personal, remuneration, work environment discrimination, management, policy, and excessive workload issues. Risk factors for major occupational stress were verified to be being female, married, with lower education levels and increased work hours, and working at critical units, nursing wards and university hospitals ${ }^{(8)}$.

Particularly in Neonatal Intensive Care Units (NICU), inappropriate personnel sizing is considered the most common stressor, and nurses have been seeking to improve work team in their units ${ }^{(9)}$. There is also an association between the number of nurses in the unit and patient mortality rate ${ }^{(10)}$.

In these neonatal care environments, occupational stressors must be better studied, since they involve peculiar aspects of caring for newborns and the practice setting as a whole, which differs from other healthcare contexts. Quantity and quality of communication with the medical staff, the physical environment, and the regulations of NICU are some of these aspects. The physical environment must be frequently reexamined, accounting for family comfort in addition to the clinical care of babies ${ }^{(11)}$.

In face of this, the objective was to assess the nursing professional practice environment in neonatal units and its relation with the levels and main sources of occupational stress.

\section{METHOD}

\section{Design of Study}

This is a cross-sectional, exploratory, descriptive, correlational study which aimed at testing relations among psychosocial variables.

\section{LOCAL}

It was performed in the neonatal intensive and medium risk care units of four public hospitals in Fortaleza, Ceará state, Brazil. The hospitals were selected due to being the largest in the public health network of Ceará, providing care to all of the state's population and to neighboring states in different health areas. Three of them are certified as teaching hospitals, and one of them is a University Hospital. All of them promote care, teaching, research, and extension activities and are considered references for high complexity neonatal care in the city of Fortaleza.

\section{Selection Criteria}

The study's population included all nursing workers of the NICU and medium risk units of the four hospitals. The sample was defined by the availability and acceptance of nurses and nursing technicians in participating of this research. All those who met the inclusion criteria (being part of the nursing team that provides direct care to patients and having worked at the unit for one year or more) were invited to participate in the research. Professionals who were on leave during the data collection period were excluded.

\section{Data Collection}

The data collection was performed from October to December 2018. Those who agreed to participate in the research received the following instruments: a sociodemographic and occupational questionnaire, the Brazilian version of Practice Environment Scale (PES) and the Work Stress Scale (WSS).

The sociodemographic and occupational questionnaire was developed by the authors, contemplating the following variables: gender, marital status, age, duration of Nursing education (number of years since the conclusion of technical and/or undergraduate course), time working at the service (years working at the unit), time working with neonatology (years working with this specific area), post-graduation, number of jobs, weekly workload, and type of employment bond.

The PES - Brazilian Version is a scale which was adapted and validated for the Brazilian culture, with the objective of assessing the professional practice nursing environment. Its validation study demonstrated appropriate psychometric properties, with Cronbach alpha coefficient ranging from 0.76 to 0.87 among subscales ${ }^{(12)}$. The reliability and validity of the Brazilian version of PES were also assessed with nursing technicians and auxiliaries, which obtained a Cronbach alpha coefficient of 0.70 to 0.88 among subscales ${ }^{(4)}$.

The scale is composed of 24 items distributed into five subscales: 1 . Nurse participation in hospital affairs; 2. Foundations for quality of care; 3 . Nurse manager ability and leadership; 4. Resource adequacy; and 5. Collegial nurse-physician relations ${ }^{(12)}$. It is a Likert-type scale whose score ranges from 1 - Completely disagree to 4 - Completely agree and is interpreted through the assessment of means per item and dimension. Means over 2.5 classify the environment as favorable, under 2.5 as unfavorable and the neutral point (2.5) may be called a mixed environment ${ }^{(12)}$.

The Work Stress Scale (WSS) is an overall occupational stress instrument which may be used in diverse work environments. Its factor analysis had obtained a Cronbach alpha coefficient of 0.91 , showing satisfactory psychometric 
characteristics, and may contribute to studies on the theme and for organizational diagnosis ${ }^{(13)}$.

This is self-administered, single-factor instrument composed of 23 items analyzed through a five-point Likerttype scale $(1$ - completely disagree to 5 - completely agree). The scale has one stressor and one reaction in each of its items. The total WSS score is the sum of the scores attributed to each item divided by the total number of scale items, with calculation of the arithmetic mean. It is assessed per means: 1.0 to 1.9 - little or no stress; 2.0 to 2.5 - intermediate stress level; and over 2.5 - high level of occupational stress ${ }^{(13)}$.

The participants have responded the instruments during their work shift individually, in their respective sectors in strategical moments which were scheduled with unit immediate coordinators.

\section{Data Analysis and Treatment}

Data treatment was performed through statistical package IBM SPSS, version 23.0. The continuous quantitative variables were analyzed for their means and standard deviations and the qualitative variables were investigated for their simple and percentage frequencies.

Variable distribution normality was verified with the Kolmogorov Sminorv Test and a non-normal distribution $(p<0.05)$ was identified., leading to the application of the Spearman's $r$ correlation test to verify the existence of and correlation force between PES and WSS. Pearson's chi-squared and Likelihood Ratio tests were also applied to verify the existence of an association among all the PES subscales and WSS categories, considering a 5\% statistical significance level, as well as the Mann-Whitney U test, to verify the distribution difference among the items of PES and stress levels per professional category.

\section{Ethical AspeCts}

This project was approved by the Research Ethics Committee in Opinion n. 2950880/18. All participants have signed the Informed Consent Form (ICF) in two copies with guarantee of anonymity and each ICF was put into a single envelope, separate from questionnaires. All the collected instruments were inserted into an envelope containing only the identification number which referred to the order of research participation. It was also emphasized that consent could be withdrawn at any phase of the study and benefits in terms of improvements in work environment management and in organizational processes with focus on patient safety have been clarified.

\section{RESULTS}

The study participants amounted to 269 Nursing workers: 96 (35.7\%) nurses and 173 (64.3\%) Nursing technicians. Out of the total sample, 215 (79.9\%) work at an NICU, $48(17.8 \%)$ at a medium risk unit and $6(2.2 \%)$ at both units. They were predominantly women (266) (98.9\%) and a little more than half were unmarried (149) (55.4\%), with a mean of $37.8( \pm 9.2)$ years of age. Considering duration of education (years since undergraduate or technical course), the mean was $12.3( \pm 8.0)$ years, whereas duration of work at neonatology was $8.3( \pm 7.1)$ years and time working at the institution was $8.0( \pm 7.7)$ years.

Most nurses $(90=93.7 \%)$ reported having concluded a postgraduation on their work area. More than half $(161=59.9 \%)$ reported having only one job and $108(40.1 \%)$ mentioned two employment bonds. Concerning weekly workload, 138 professionals (51.3\%) reported working up to 44 hours per week, although the overall mean of worked hours was higher (47.6 hours per week). Regarding the type of employment bond, 113 were public servants (42.0\%), 85 were cooperative workers (31.6\%), 67 were registered $(24.9 \%)$ and $3(1.1 \%)$ had more than one of the previous bonds.

Table 1 presents the distribution of means and their respective standard deviations of items for the Brazilian version of PES in the investigated hospitals.

Most items are observed to be favorable to the nursing professional practice environment (means over 2.5) with an emphasis on collegial nurse-physician relations (subscale 5) as the best assessed dimension. On the other hand, resource adequacy (subscale 4) was assessed as unfavorable to professional practice, with emphasis on items 8 and 10, which deal with personnel sizing.

Table 2 shows the means and standard deviations of the Work Stress Scale.

The prevalence of factors which contribute to a low to intermediate level of occupational stress (means up to 2.5) are noticed to be predominant. Five aspects pointed out by the team as high-level stress generators (means over 2.5) are emphasized; these are related to task distribution, lack of information/feedback on organizational decisions, favoritism at the work environment, little perspective of career growth, and available time to perform a certain amount of work.

Table 3 shows the association between the variables practice environment assessment and stress levels at work as per the perception of all participants.

A significant statistical association is observed between professional practice environment and work environment stress $(p<0.001)$. Also, most of those who assessed their practice environment as unfavorable presented a higher level of stress $(81.3 \%)$ in comparison with those who assessed their units as favorable (80.1\%).

Table 4 shows the mean differences for items of the assessment of the professional practice environment which had the highest influence on occupational stress levels per category (nurses and nursing technicians).

There were differences in the relations between stress levels and practice environment assessment by nurses and nursing technicians, with the highest differences among those with intermediate stress. A significant statistical difference was found in the assessment for a sufficient number of professionals for quality care (items 8 to 10) ( $p=0.004$ and $p=0.002$, respectively). These items were predictors of a high stress level for both categories and, consequently, they have reflected an unfavorable assessment of practice environment. These factors were also more stressful for nursing technicians. 
Table 1 - Distribution of means and standard deviations of assertions in the Brazilian Version of PES in the investigated hospitals Fortaleza, CE, Brazil, 2018.

\begin{tabular}{|c|c|}
\hline Subscales and assertions & Mean $( \pm \mathrm{SD})$ \\
\hline Subscale 1 - Nurse participation in hospital affairs & $2.69( \pm 0.7)$ \\
\hline 05. Career development/clinical ladder opportunity. & $2.61( \pm 1.0)$ \\
\hline 13. Opportunities for advancement. & $2.90( \pm 0.9)$ \\
\hline 17. Administration that listens and responds to employee concerns. & $2.42( \pm 0.9)$ \\
\hline 22. Nursing administrators consult with staff on daily problems and procedures. & $2.86( \pm 0.9)$ \\
\hline Subscale 2 - Foundations for quality of care & $2.88( \pm 0.5)$ \\
\hline 04. Active staff development or continuing education programs for nurses. & $3.08( \pm 0.8)$ \\
\hline 14. A clear philosophy of nursing that pervades the patient care environment. & $2.90( \pm 0.8)$ \\
\hline 15. Working with nurses who are clinically competent. & $3.18( \pm 0.7)$ \\
\hline 18. An active quality assurance program. & $2.76( \pm 0.9)$ \\
\hline 21. A preceptor program for newly hired RNs. & $2.74( \pm 0.8)$ \\
\hline 23. Written, up-to-date nursing care plans for all Patients. & $2.94( \pm 0.9)$ \\
\hline 24. Patient care assignments that foster continuity of care, i.e., the same nurse cares for the patient from one day to the next. & $2.57( \pm 1.0)$ \\
\hline Subscale 3 - Nurse manager ability and leadership & $2.76( \pm 0.7)$ \\
\hline 03. A supervisory staff that is supportive of the nurses. & $3.06( \pm 0.8)$ \\
\hline 06. Supervisors use mistakes as learning opportunities, not criticism. & $2.68( \pm 0.9)$ \\
\hline 09. A nurse manager who is a good manager and leader. & $2.95( \pm 0.8)$ \\
\hline 11. Praise and recognition for a job well done. & $2.51( \pm 1.0)$ \\
\hline 16. A nurse manager who backs up the nursing staff in decision making, even if the conflict is with a physician. & $2.63( \pm 0.9)$ \\
\hline Subscale 4 - Resource adequacy & $2.41( \pm 0.7)$ \\
\hline 01. Adequate support services allow me to spend time with my patients. & $2.69( \pm 0.9)$ \\
\hline 07. Enough time and opportunity to discuss patient care problems with other nurses. & $2.58( \pm 0.9)$ \\
\hline 08. Enough registered nurses to provide quality patient care. & $2.21( \pm 1.1)$ \\
\hline 10. Enough staff to get the work done. & $2.19( \pm 1.0)$ \\
\hline Subscale 5 - Collegial nurse-physician relations & $2.97( \pm 0.6)$ \\
\hline 02. Physicians and nurses have good working relationships. & $3.12( \pm 0.7)$ \\
\hline 12. A lot of team work between nurses and physicians. & $2.93( \pm 0.8)$ \\
\hline 20. Collaboration (joint practice) between nurses and physicians. & $2.86( \pm 0.7)$ \\
\hline Overall scale & $2.75( \pm 0.5)$ \\
\hline
\end{tabular}

SD: standard deviation from the mean.

\section{DISCUSSION}

The participants' profile corroborates other studies performed with the nursing team in neonatal care environments, which have shown a prevalence of women, nursing technicians, young adults with experience in the area (time of education and of service and specialization) and viable workload ${ }^{(14-19)}$. Upon assessment of nursing practice environment in NICU (Table 1), a predominance of favorable aspects is perceived in four of the five subscales of PES, a fact which was demonstrated by a multicenter study with 1247 NICU nurses of North American hospitals ${ }^{(20)}$, whose scores ranged from 1.93 and 3.79, with an overall mean of $2.88( \pm 0.32)$, characterizing favorable environments for nursing team practice ${ }^{(20)}$.

In this study, it should be emphasized, the subscale related to resource adequacy was shown to be unfavorable, confirming results of a different study performed with
404 nurses in hospitals in Saudi Arabia ${ }^{(21)}$. In this investigation, precarious nursing practice environments and high rates of patients per nurse contributed to negative results in the nursing work.

The unfavorable assessment of resource adequacy, as well as the shortage of personnel and work overload, is a common issue in many countries and, worryingly, in Brazilian public hospitals ${ }^{(22-24)}$. These conditions are due to the lack of recognition of this profession, precariousness of health work, and low remuneration, leading to the necessity of multiple jobs. This a vicious cycle, since this search generates work overload, which by its turn leads to burnout and absenteeism, partially explaining the shortage of personnel.

A study with nursing teams in four large-sized states in the USA classified NICU for their unperformed/neglected nursing care and analyzed their associated factors. The variables included the patient's degree of dependence, 
Table 2 - Distribution of means and standard deviations of Work Stress Scale statements as attributed by nursing professionals Fortaleza, CE, Brazil, 2018.

\begin{tabular}{|c|c|c|}
\hline Item & Statement & Mean $( \pm \mathrm{SD})$ \\
\hline 01 & The distribution of tasks in my area has been making me nervous. & $2.55( \pm 1.1)$ \\
\hline 02 & My work's type of control irritates me. & $2.32( \pm 0.9)$ \\
\hline 03 & The lack of autonomy in my work is distressing. & $2.42( \pm 1.0)$ \\
\hline 04 & I have been feeling upset about the lack of confidence of my superior on my work. & $2.02( \pm 1.0)$ \\
\hline 05 & I feel irritated with the deficiency in disseminating information on organizational decisions. & $2.83( \pm 1.2)$ \\
\hline 06 & I feel upset about the lack of information about my tasks at work. & $2.32( \pm 1.0)$ \\
\hline 07 & I am irritated at the lack of communication between my colleagues and me. & $2.10( \pm 1.0)$ \\
\hline 08 & I feel upset because my superior treats me poorly in front of my coworkers. & $2.16( \pm 1.3)$ \\
\hline 09 & Performing tasks which are beyond my capacity bothers me. & $2.42( \pm 1.3)$ \\
\hline 10 & I get in a bad mood having to work for many hours straight. & $2.45( \pm 1.3)$ \\
\hline 11 & The communication between me and my superior bothers me. & $2.00( \pm 1.0)$ \\
\hline 12 & I get upset with discrimination/favoritism in my work environment. & $2.86( \pm 1.3)$ \\
\hline 13 & I am bothered by the deficiency in professional training. & $2.47( \pm 1.2)$ \\
\hline 14 & I get in a bad mood because I feel isolated in the organization. & $1.89( \pm 0.9)$ \\
\hline 15 & I am irritated because my superiors undervalue me. & $2.48( \pm 1.2)$ \\
\hline 16 & The little perspective of career growth has been distressing me. & $2.68( \pm 1.3)$ \\
\hline 17 & I have been feeling upset for working at tasks below my skills. & $1.93( \pm 0.9)$ \\
\hline 18 & Competition at my work environment has been putting me in a bad mood. & $1.99( \pm 0.9)$ \\
\hline 19 & The lack of comprehension on what my responsibilities are at this work have been irritating me. & $2.16( \pm 0.9)$ \\
\hline 20 & I have been feeling nervous because my superior gives me contradictory orders. & $1.94( \pm 1.0)$ \\
\hline 21 & I feel irritated because my superior hides my well-done work in front of other people. & $2.05( \pm 1.0)$ \\
\hline 22 & Insufficient time to perform the amount of work I have makes me nervous. & $2.59( \pm 1.2)$ \\
\hline 23 & I feel upset by my superior avoiding giving me important responsibilities. & $1.91( \pm 0.8)$ \\
\hline \multicolumn{2}{|c|}{ Overall scale } & $2.28( \pm 0.6)$ \\
\hline
\end{tabular}

SD: standard deviation from the mean.

Table 3 - Distribution of the total of participants as per assessment of professional practice environment and nursing work-related stress levels in neonatal units - Fortaleza, CE, Brazil, 2018.

\begin{tabular}{|c|c|c|c|c|c|}
\hline \multirow[b]{2}{*}{ Practice environment (PES) } & \multicolumn{5}{|c|}{ Stress levels (WSS) } \\
\hline & $\begin{array}{c}\text { Low or none } \\
\text { n (\%) }\end{array}$ & $\begin{array}{c}\text { Intermediate } \\
\text { n (\%) }\end{array}$ & $\begin{array}{l}\text { High } \\
\text { n (\%) }\end{array}$ & $\begin{array}{l}\text { Total } \\
\text { n (\%) }\end{array}$ & $\mathbf{p}^{*}$ \\
\hline Unfavorable & $15(18.8)$ & $27(33.8)$ & $38(47.5)$ & $80(100.0)$ & \\
\hline Mixed & $2(11.1)$ & $10(55.6)$ & $6(33.3)$ & $18(100.0)$ & $<0.001$ \\
\hline Favorable & $65(38.0)$ & $72(42.1)$ & $34(19.9)$ & $171(100.0)$ & \\
\hline Total & $82(30.5)$ & $109(40.5)$ & $78(29.0)$ & $269(100.0)$ & \\
\hline
\end{tabular}

*Likelihood ratio p.

patient/nurse ratio, professional characteristics of the nursing team, work environment, and lost nursing care in the last shift. In high-risk hospitals, neonates have lost nearly $50 \%$ more of nursing care and the smallest the nursing team, the higher were the chances of neglected care ${ }^{(2)}$.

It is possible to observe that, in practice, the NICU frequently presents demand which is higher than its occupation capacity. A study suggests that there is a relation between high demand and early discharges and care in a higher level of complexity than recommended, showing the need for even more nursing professionals, mainly nurses, for baby monitoring ${ }^{(23)}$. It is thus evident the importance of the need for appropriateness and the constant personnel sizing monitoring in neonatal units.

The problems related to nursing personnel sizing are thus understood to expose patients to diverse risks, including inappropriate treatment, errors related to nursing care, increase in adverse events, and unperformed care, in addition to exposing professionals to work overload and its consequences, such as stress and burnout. For neonates, neglected 
Table 4 - Differences in the mean distribution of PES - Brazilian version items and stress levels per professional category - Fortaleza, CE, Brazil, 2018.

\begin{tabular}{|c|c|c|c|c|c|c|c|c|c|}
\hline \multirow{3}{*}{$\begin{array}{l}\text { PES statement - } \\
\text { Brazilian version }\end{array}$} & \multicolumn{9}{|c|}{ Stress levels (WSS) } \\
\hline & \multicolumn{3}{|c|}{ Low or none } & \multicolumn{3}{|c|}{ Intermediate } & \multicolumn{3}{|c|}{ High } \\
\hline & Nur. & Tech. & p-value* & Nur. & Tech. & p-value* & Nur. & Tech. & $p$-value* \\
\hline PES2 & 3.19 & 3.42 & 0.040 & 2.98 & 3.19 & 0.053 & 2.59 & 3.04 & 0.030 \\
\hline PES4 & 3.00 & 3.38 & 0.193 & 2.88 & 3.31 & 0.006 & 2.48 & 2.96 & 0.018 \\
\hline PES7 & 2.59 & 2.93 & 0.195 & 2.40 & 2.78 & 0.033 & 1.96 & 2.37 & 0.103 \\
\hline PES8 & 2.93 & 2.16 & 0.004 & 2.29 & 2.07 & 0.272 & 2.44 & 1.86 & 0.014 \\
\hline PES10 & 2.89 & 2.09 & 0.002 & 2.36 & 2.04 & 0.080 & 2.41 & 1.84 & 0.012 \\
\hline PES12 & 3.15 & 3.22 & 0.315 & 2.74 & 3.04 & 0.011 & 2.33 & 2.82 & 0.017 \\
\hline PES14 & 3.33 & 3.11 & 0.462 & 2.64 & 3.16 & 0.001 & 2.41 & 2.55 & 0.411 \\
\hline PES18 & 2.96 & 2.85 & 0.688 & 2.69 & 3.00 & 0.040 & 2.30 & 2.53 & 0.215 \\
\hline PES19 & 2.74 & 3.02 & 0.141 & 2.52 & 3.07 & 0.002 & 2.30 & 2.51 & 0.300 \\
\hline PES20 & 2.96 & 3.13 & 0.313 & 2.71 & 3.03 & 0.024 & 2.37 & 2.69 & 0.068 \\
\hline PES23 & 2.89 & 3.27 & 0.061 & 2.64 & 3.09 & 0.010 & 2.74 & 2.78 & 0.803 \\
\hline PES24 & 3.11 & 2.42 & 0.008 & 2.64 & 3.02 & 0.141 & 2.70 & 2.37 & 0.165 \\
\hline
\end{tabular}

*Mann-Whitney $\cup p$.

care may be fatal: not changing diapers, for example, may result in dermatitis and, consequently, in infections that may lead babies to death.

Among the possibilities pointed out for nursing workload, appropriate quantity of human resources is emphasized as indispensable to quality of care. Thus, with this appropriateness of personnel sizing, it is possible to guarantee nursing care with lower indexes of adverse events ${ }^{(22)}$.

Concerning the good work relations of the nursing team with the medical team, other studies using the scale which gave origin to PES, Nursing Work Index Revised - Brazilian Version (NWI-R) have found similar data concerning this factor $^{(16-17,19-20)}$. On the other hand, in a recent Brazilian study, Nursing work team performance was shown to be possibly undermined by excessive pressure and medical team demands, leading to stressful work hours ${ }^{(21)}$.

Regarding stress level assessment (Table 2), the low and moderate levels shown in this investigation among most participants are considered a positive aspect of the study, since the reality of nursing work in most Brazilian public institutions has been associated to high levels of stress and consequent organizational illness ${ }^{(19)}$. The data identified through WSS analysis have confirmed the findings of an international study related to low levels of burnout among workers in nine NICU in Switzerland ${ }^{(25)}$. Although burnout levels are not an object of study of this work, stress is known to evolve and be the source of this syndrome in the context of worker health and in the nursing work environment. Data of Brazilian studies have revealed higher indexes of this syndrome related to professional exhaustion. Nurses working in unfavorable conditions have more emotional exhaustion which characterizes burnout ${ }^{(19)}$. In a comparative study performed in three public hospitals in the city of São Paulo, nurses in a lower complexity unit presented a lower level of burnout ${ }^{(12)}$.

Larger sized institutions, critical units, and higher complexity units, as well as those characterized as unfavorable for practice, tend to influence stress levels, increasing its occurrence among nursing team members. Intensive care and medium-risk neonatal units are some examples of these contexts.

Another important aspect is related to excessive workload as a stressor agent, which is pointed by study participants and is the theme of several articles ${ }^{(15,26-27)}$. This workload may be classified as physiological, psychic, biological, mechanical, physical, and chemical and may also have severe outcomes and lead to illnesses among nursing team workers ${ }^{(28)}$.

Psychic workloads were also identified by nursing workers, in another study, as causing accidents and diseases, being more recurrent in the NICU environment. This load may be related to precarious infrastructure and the scarcity of appropriate materials to guarantee quality of patient care. The aforementioned work conditions lead to different psychological problems among the team, among which the most recurrent are stress, anxiety, and depression ${ }^{(28)}$.

Researchers reinforce that occupational stress is an emerging problem among those who work in intensive care environments, as these are particularly exposed to the risk of developing burnout. They argue that there is very limited evidence on the management of occupational stress and burnout in the ICU and that the singularity of NICU must be considered in the development of occupational stress management strategies. Training the self-conscience of these workers for their reactions in the NICU environment, from the pre-employment phase, may be an additional approach to preventing and controlling stress ${ }^{(29)}$. 
The identification of stressors pointed out by study participants is an aspect which must be valued for decision making by nursing managers with the objective of reducing stress in the work environment. In this study, the main stressors included task distribution, lack of information/ feedback on organizational decisions, favoritism in the work environment, little perspective of career growth, and the time to perform a certain amount of work.

Observing the association between a favorable environment for nursing team practice and a lower stress level in the studied neonatal units (Table 3), other studies have confirmed this relation ${ }^{(20,22)}$. A study conducted in Southeast Brazil has identified that unfavorable work environments are causal factors of emotional exhaustion ${ }^{(19)}$. Stress recognition by the team is an aspect that must be valued by unit managers, as this may impact the safety attitude of the institution ${ }^{(17)}$.

Analyzing the factors of the practice environment which most influenced team stress per category (Table 4), teamwork with physicians was confirmed to be a more important stressor for nurses than for the technicians, reflecting in an unfavorable practice environment in the perception of higher-level professionals $(p=0.017)$. In isolation, this data contradicts a finding from an application of the PES Brazilian version scale, whose items related to collegial nurse-physician relations were well-evaluated. In sum, correlating the constructs, although relevant in the nurses' assessment of the quality of their practice environment, this factor was noticed to be an important stressor in the studied setting, followed by insufficient number of professionals.

The difference is in the work process of nurses and technicians in the studied hospitals, which were similar to those of other neonatal care services in Brazil, must be emphasized. Nurses are responsible for unit management and for more invasive and critical care, such as passing the peripherally inserted central catheter, aspiration, catheterization, probing, and other tasks. Nursing technicians by their turn perform more direct, continuous, and repetitive care towards babies, such as diaper change, medication administration, and diet, which require attention to precise calculations which newborns require; these may lead to a higher physical and mental overload.

It is thus necessary to emphasize the differences of work of both categories when searching to understand the multiple sources of stress, which, in this study, were shown to be remarkably distinct. Nurses tend to have a high level of stress when faced with absence of work team with physicians and issues related to care continuity. On the other hand, for the technicians, the main sources of stress are related to work overload, understaffing and the exceeding number of babies per work shift, which increases the overload of the whole team, possibly causing visible and invisible damage to newborn safety.

In this sense, a clear association between the number of patients per nursing professional and the impact on quality of care, a consequence of a stressful work environment, are noticeable. A study shows that occasionally nursing professionals experience at least one stressful event in their work shifts, but nurses feel more capable of coping with stress and do not think of leaving their jobs in the NICU for this reason. In the same study, the main stressor identified by nurses was the inappropriateness of human resources. Among the ways of coping with stressor agents, concentration on activities and realistic problem analysis aiming at intervening in the best possible way, clarity concerning the attributions of each category, and a positive outlook of work environment were emphasized ${ }^{(9)}$. These thoughts translate into a cohesive nursing team, with safety and high self-esteem. These characteristics are believed to be acquired throughout time through training and interaction between managers and workers so as to promote team maturation; it is important to consider the possibility of working in environments which favor nursing practice.

The statistical analysis which was applied to assess the relation between professional practice environment and the stress levels of NICU nursing workers have presented the expected results, since the professionals who reported lower stress levels assessed their work environments as favorable to nursing practice. The results of this research are thus believed to be relevant to guide decision-making by managers and leaders in this area, aiming at correcting unfavorable aspects and consequently improving the nursing professional practice environment, directly impacting the improvement of patient care and their clinical responses.

This study is limited by its cross-sectional design and sample specificity, suggesting that the presented data cannot be generalized to any context or patient, since they represent the reality of a singular environment of nursing practice. However, its potential for collaborating with the advancement of knowledge in this area and for Neonatal Nursing practice and research is emphasized, since by recognizing the most evident stressors for the practice of these professionals, effective and significant interventions directed at the maintenance of physical and mental health of nurses and nursing technicians can be planned.

Some measures can be adopted to minimize the aspects pointed out by this study, such as the elaboration of strategies targeted at developing self-control, positive reassessment, and social support for the nursing team, centered both on emotion and on the issue, since these lead to decisionmaking in solving the stressful situation or the potentially stressful event ${ }^{(30)}$; planning permanent education actions so as to sensitize and instrumentalize workers to use strategies that minimize work stress ${ }^{(30)}$; daily measurement of workload based on nursing prognosis indexes; task redistribution considering characteristics of the team (skills, time at work, experience) and the patients; and team resizing, following on-duty work demands and based on quality indicators.

Investment in these work environments may be promising strategies to substantially improve the results of patients who, due to being in neonatal care units, are more vulnerable, not only due to their clinical conditions, but also due to their full dependence on the team and appropriate unit structure to manage safe care to these patients. 


\section{CONCLUSION}

There is inversely proportional relationship between practice environment and nursing team stress levels in neonatal units, demonstrated by the higher level of stress among those who assessed their units as unfavorable to professional practice.

The main factors attributed to practice environment quality include the nurse-physician relations, the nurse participation in hospital affairs, the nurse manager ability and leadership and foundations for quality care. As main work stressors of nursing in the NICU, task distribution, lack of information/feedback on organizational decisions, favoritism in the work environment, little perspective of career growth, and time to perform a certain amount of work were verified.

Nurse stress levels are emphasized to be higher mainly due to factors such as absence of teamwork with physicians and lack of care continuity, whereas work overload and understaffing are the major sources of stress for nursing technicians. This difference should be the object of new studies that approached the impact of these stressors on newborn safety.

\section{RESUMO}

Objetivo: Avaliar o ambiente de prática profissional da enfermagem em unidades neonatais e sua relação com os níveis e as principais fontes de estresse ocupacional. Método: Estudo transversal, descritivo, exploratório e correlacional, realizado com profissionais de enfermagem das unidades neonatais de quatro hospitais públicos. Aplicaram-se o questionário sociodemográfico/profissional, Versão Brasileira da Practice Environment Scale e a Escala de Estresse no Trabalho. Na análise, adotaram-se média, desvio padrão e testes quiquadrado de Pearson, Razão de Verossimilhança e U de Mann Whitney para associação entre variáveis. Resultados: Participaram 269 profissionais. O ambiente de prática foi avaliado como favorável por mais da metade da amostra (63,6\%), demonstrando associação estatística significante e inversamente proporcional com o estresse ocupacional ( $\mathrm{p}<0,001)$. O número insuficiente de profissionais para um cuidado de qualidade foi a maior fonte de estresse para as técnicas de enfermagem, enquanto o trabalho em equipe com médicos foi fator preponderante na avaliação da qualidade do ambiente e do nível de estresse elevado para as enfermeiras. Conclusão: Ambientes de prática desfavoráveis aumentam o nível de estresse de profissionais de enfermagem em unidades neonatais, podendo comprometer a segurança do paciente.

\section{DESCRITORES}

Enfermagem Neonatal; Ambiente de Trabalho; Estresse Ocupacional; Relações Médico-Enfermeiro; Unidades de Terapia Intensiva Neonatal.

\section{RESUMEN}

Objetivo: Evaluar la práctica profesional de enfermería en unidades neonatales y su relación con los niveles y las principales fuentes de estrés ocupacional. Método: Estudio transversal, descriptivo, exploratorio y correlacional conducido con profesionales de enfermería de unidades neonatales de cuatro hospitales públicos. Se aplicaron el cuestionario sociodemográfico/profesional, la versión brasileña de Practice Environment Scale y la Escala de Estrés en el Trabajo. En el análisis, se adoptaron la media, la desviación típica y las pruebas chi-cuadrado de Pearson, Razón de Verosimilitud y Mann Whitney U para la asociación entre las variables. Resultados: Los participantes fueron 269 profesionales. El ambiente de práctica fue evaluado como favorable por más de la mitad de la muestra (63,6\%), con una asociación estadística significativa e inversamente proporcional con el estrés ocupacional ( $<<0,001)$. El número insuficiente de profesionales para una atención de calidad fue la mayor fuente de estrés para las técnicas de enfermería, mientras que el trabajo en equipo con los médicos fue el factor predominante en la evaluación de la calidad del ambiente y del nivel de estrés elevado para las enfermeras. Conclusión: Los ambientes de práctica desfavorables aumentan el nivel de estrés de los profesionales de enfermería en las unidades neonatales y pueden comprometer la seguridad del paciente.

\section{DESCRIPTORES}

Enfermería Neonatal; Ambiente de Trabajo; Estrés Laboral; Relaciones Médico-Enfermero; Unidades de Cuidado Intensivo Neonatal.

\section{REFERENCES}

1. Lake ET. Development of the practice environment scale of the Nursing Work Index. Res Nurs Health. 2002;25(3):176-88. https://doi.org/10.1002/nur.10032

2. Lake ET, Staiger D, Edwards EM, Smith JG, Rogowski JA. Nursing care disparities in neonatal intensive care units. Health Serv Res. 2018;53 Suppl 1:3007-26. http://dx.doi.org/10.1111/1475-6773.12762

3. Zangaro GA, Jones K. Practice environment scale of the Nursing Work Index: a reliability generalization meta-analysis. West J Nurs Res. 2019;41(11):1658-84. http://dx.doi.org/10.1177/0193945918823779

4. Gasparino RC, Martins MCP, Alves DFS, Ferreira TDM. Validation of the Practice Environment Scale among nursing technicians and aides. Acta Paul Enferm. 2020;33:eAPE20190243. https://doi.org/10.37689/acta-ape/2020ao0243

5. Sarafis $P$, Rousaki E, Tsounis A, Malliarou M, Lahana L, Bamidis $P$, et al. The impact of occupational stress on nurses' caring behaviors and their health related quality of life. BMC Nurs. 2016;15:56. https://doi.org/10.1186/s12912-016-0178-y6.

6. Luan X, Wang P, Hou W, Chen L, Lou F. Job stress and burnout: a comparative study of senior and head nurses in China. Nurs Health Sci. 2017;19(2):163-9. http://dx.doi.org/10.1111/nhs.12328

7. Sun J, Bai H, Jiahuan L, Lin P. Predictors of occupational burnout among nurses: a dominance analysis of job stressors. J Clin Nurs. 2017;26:23-4. http://dx.doi.org/10.1111/jocn.13754

8. Kakemam E, Raeissi P, Raoofi S, Soltani A, Sokhanvar M, Visentin DC, et al. Occupational stress and associated risk factors among nurses: a cross-sectional study. Contemp Nurse. 2019;55(2-3):237-49. http://dx.doi.org/10.1080/10376178.2019.1647791 
9. Fiske E. Nurse stressors and satisfiers in the NICU. Adv Neonatal Care. 2018;18(4):276-84. https://doi.org/10.1097/ANC.0000000000000514

10. Corchia C, Fanelli S, Gagliardi L, Bellù R, Zangrandi A, Persico A, et al. Work environment, volume of activity and staffing in neonatal intensive care units in Italy: results of the SONAR-nurse study. Ital J Pediatr. 2016;42:34. https://doi.org/10.1186/s13052-016-0247-6

11. Williams KG, Patel KT, Stausmire JM, Bridges C, Mathis MW, Barkin JL. The Neonatal Intensive Care Unit: environmental stressors and supports. Int J Environ Res Public Health. 2018;15(1):60. https://doi.org/10.3390/ijerph15010060

12. Gasparino RC, Guirardello EB. Validation of the Practice Environment Scale to the Brazilian culture. J Nurs Manag. 2017;25(5):375-83. https://doi.org/10.1111/jonm.12475

13. Paschoal T, Tamayo A. Validação da escala de estresse no trabalho. Estud Psicol (Natal). 2004;9(1):45-52. https://doi.org/10.1590/S1413294X2004000100006

14. Azevedo Filho FM, Rodrigues MCS, Cimiotti JP. Nursing practice environment in intensive care units. Acta Paul Enferm. 2018;31(2): 217-23. https://doi.org/10.1590/1982-0194201800031

15. Boaretto F, Haddad MCFL, Rossaneis MA, Gvozd R, Pissinati PSC. Contexto de ambiente de trabalho entre enfermeiras assistenciais em hospital universitário. Cogitare Enferm. 2016;21(2):1-10. http://dx.doi.org/10.5380/ce.v21i2.44006

16. Dorigan GH, Guirardello EB. Nursing practice environment, satisfaction and safety climate: the nurses' perception. Acta Paul Enferm. 2017;30(2):129-35. https://doi.org/10.1590/1982-0194201700021

17. Guirardello E. Impact of critical care environment on burnout, perceived quality of care and safety attitude of the nursing team. Rev Latino Am Enfermagem. 2017;25:e2884. https://doi.org/10.1590/1518-8345.1472.2884

18. Lavoie-Tremblay M, Feeley N, Lavigne GL, Genest C, Robins S, Fréchette J. Neonatal Intensive Care Unit nurses working in an open ward: stress and work satisfaction. Health Care Manag (Frederick). 2016;35(3):205-16. https://doi.org/10.1097/HCM.0000000000000122

19. Nogueira LS, Sousa RMC, Guedes ES, Santos MA, Turrini RNT, Cruz DALM. Burnout and nursing work environment in public health institutions. Rev Bras Enferm. 2018;71(2):336-42. http://dx.doi.org/10.1590/0034-7167-2016-0524

20. Lake ET, Hallowell SG, Kutney-Lee A, Hatfield LA, Guidice MD, Boxer BA, et al. Higher quality of care and patient safety associated with better NICU work environments. J Nurs Care Qual. 2016;31(1):24-32. https://doi.org/10.1097/NCQ.0000000000000146

21. Ambani Z, Kutney-Lee A, Lake ET. The nursing practice environment and nurse job outcomes: a path analysis of survey data. J Clin Nurs. 2020;29(13-14):2602-14. https://doi.org/10.1111/jocn.15283

22. Luna AA, Branco LLWV, Beleza LO. Carga de trabalho em UTI neonatal: aplicação da ferramenta nursing activities score. Rev Online Pesq Cuid Fundam. 2017;9(1):144-51. http://dx.doi.org/10.9789/2175-5361.2017.v9i1.144-151

23. Curan GRF, Beraldo A, Souza SNDH, Rossetto EG. Dimensionamento de pessoal de unidades neonatais em um hospital universitário. Semin Ciênc Biol Saúde. 2015;36 Supl 1:55-62. http://dx.doi.org/10.5433/1679-0367.2015v36n1Suplp55

24. Rodrigues CM, Costa KES, Antunes AV, Gomes FA, Rezende GJ, Silva DV. Carga de trabalho e dimensionamento de pessoal de enfermagem em Unidades de Terapia Intensiva. Rev Aten Saúde (São Caetano do Sul). 2017;15(53):5-13. https://doi.org/10.13037/ras.vol15n53.4159

25. Klein SD, Bucher HU, Hendriks MJ, Baumann-Hölzle R, Streuli JC, Berger TM, et al. Sources of distress for physicians and nurses working in Swiss neonatal intensive care units. Swiss Med Wkly. 2017;147:w14477. https://doi.org/10.4414/smw.2017.14477

26. Carvalho DP, Rocha LP, Barlem JGT, Dias JS, Schallenberger CD. Cargas de trabalho e a saúde do trabalhador de enfermagem: revisão integrativa. Cogitare Enferm. 2017;22(1):1-10. http://dx.doi.org/10.5380/ce.v22i1.46569

27. Karino ME, Felli VEA, Sarquis LMM, Santana LL, Silva SR, Teixeira RC. Cargas de trabalho e desgastes dos trabalhadores de enfermagem de um hospital-escola. Ciênc Cuid Saúde. 2015;14(2):1011-8. https://doi.org/10.4025/cienccuidsaude.v14i2.21603

28. Michaello RS, Tomaschewski-Barlem JGT, Carvalho DP, Rocha LP, Bordignon SS, Neutzling RS. Perception of nursing workers about the workloads in a neonatal intensive care unit. Rev Online Pesq Cuid Fundam. 2020;12:54-61. http://dx.doi.org/10.9789/2175-5361.rpcfo. v12.6983

29. Bresesti I, Folgori L, Bartolo P. Interventions to reduce occupational stress and burn out within neonatal intensive care units: a systematic review. Occup Environ Med. 2020;77(8):515-9. http://dx.doi.org/10.1136/oemed-2019-106256

30. Moraes F, Benetti ERR, Herr GEG, Stube M, Stumm EMF, Guido LA. Estratégias de coping utilizadas por trabalhadores de enfermagem em terapia intensiva neonatal. Rev Min Enferm. 2016;20:e966. http://dx.doi.org/10.5935/1415-2762.20160036 